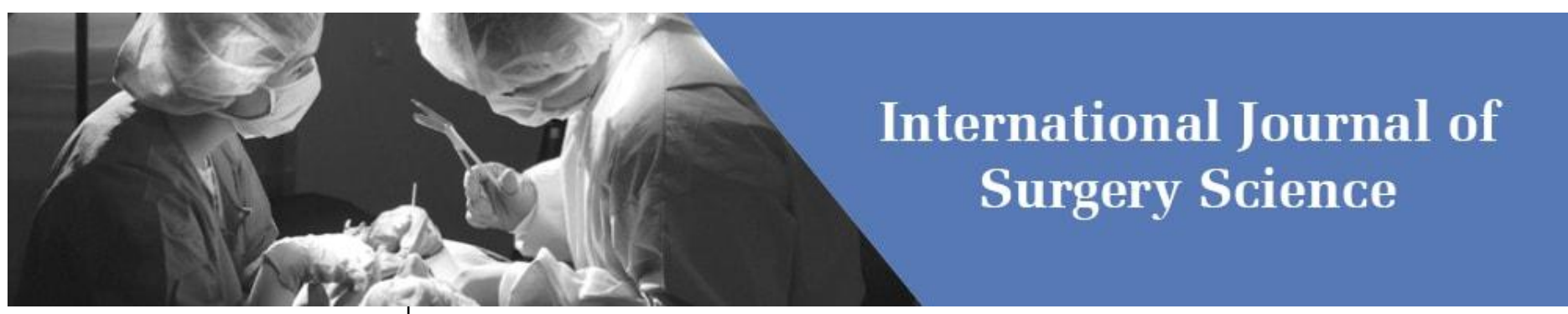

E-ISSN: 2616-3470

P-ISSN: 2616-3462

(C) Surgery Science

www.surgeryscience.com

2020; 4(3): $168-170$

Received: 22-05-2020

Accepted: 24-06-2020

Dr. Apoorv Shrivastava

Associate Professor, Department of Surgery, Index Medical College and Hospital, Indore, Madhya Pradesh, India
Corresponding Author: Dr. Apoorv Shrivastava Associate Professor, Department of Surgery, Index Medical College and Hospital, Indore, Madhya Pradesh, India

\section{A comparative study between right hemicolectomy with ileotransverse anastomosis and primary repair with or without ileostomy/Colostomy in the management of Caecal perforation}

\section{Dr. Apoorv Shrivastava}

DOI: $\underline{\text { https://doi.org/10.33545/surgery.2020.v4.i3c.488 }}$

\begin{abstract}
Background: Study was conducted in the Department of General Surgery, Index Medical College and Hospital, Indore from May 2013 to April 2016 (Three Years), 100 patients admitted to surgical emergency with acute abdomen were selected for the study.

Method: Comparative study was done between group A (right hemicolectomy with ileotransverse anastomosis) and group B (primary repair with omental patch, primary repair with defunctioning loop ileostomy, Right hemicolectomy with double barrel ileo-transverse colostomy). There was no selection criteria for patients.

Result: We found $(76 \%)$ males and the females $(24 \%)$ in our study, there was statistical significance in wound infection/serous discharge between group A and group B with $\mathrm{p}$ value $=0.047$, there was statistical insignificance found in between group A and group B with $p$ value $=0.043$ in anastomotic leak/ fistula, There was statistical significance found in outcome between group A and group B with $p$ value $=0.028$ Conclusion: Right hemicolectomy with ileotransverse anastomosis in cases of traumatic caecal perforation plays an important role in reducing the incidence of complications like wound infection, wound dehiscenes, ileostomy and colostomy related complications like weight loss and electrolyte imbalance. We recommend that Right hemicolectomy with ileotransverse anastomosis should be preferred over other surgical options, primary repair with omental patch, primary repair with defunctioning loop ileostomy, Right hemicolectomy with double barrel ileo-transverse colostomy in cases of caecal perforations in randomised study.
\end{abstract}

Keywords: Caecal Perforation, Laparotomy, Hemicolectomy \& Ileotransverse Anastomosis

\section{Introduction}

A Caecum perforation is a very rare identity. Traumatic caecal perforation are even rare. Caecal perforations are usually seen associated with entities such as diverticular disease, inflammatory bowel diseases, ogilville syndrome [1] closed loop obstructions, pancreatic carcinomas [2], colorectal cancers ${ }^{[3]}$, hirschsprung's disease ${ }^{[4]}$ rarely associated with foreign body, in burn patient, tuberculosis infection and following caesarean section or iatrogenic endoscopic procedure. Traumatic causes of caecal perforations are stab wounds, gunshot wounds, operative wounds and foreign body.

Surgery for colonic perforation is associated with high morbidity and mortality rates. Simple closure of the perforation without exteriorizing the caecum was the procedure most used. Exteriorization of the caecum may be necessary when the duration of the perforation has been prolonged, and when fecal contamination is present. These cases require added hospitalization, extra care for their caecostomy, and a second operation to re-place the caecum into the abdomen. Other surgical options are tube caecostomy, and right colectomy.

Perforation of healthy caecum is an uncommon condition that is clinically difficult to diagnose and differentiate from other causes of acute abdomen. Perforation of caecum is a challenging surgical problem. Caecal perforation peritonitis is a rare surgical emergency in the Indian subcontinent and in tropical countries.

Various causes include traumatic, obstruction, inflammatory disease, malignancy etc. Isolated caecal perforation is rare. Caecal perforation are usually seen associated with entities such as diverticular disease, inflammatory bowel diseases, ogilville syndrome ${ }^{[1]}$, closed loop 
obstruction, pancreatic carcinoma [2], colorectal cancers [3] Hirschprungs disease ${ }^{[4]}$ etx, in presence of patent ileo-caecal valve. Perforation from different causes present individual problems and demand specific management. The mortality of perforated caecum is high, varying from $35 \%$ to $72 \%$. (ALBERS, SMITH AND CARTER).

\section{Material \& Method}

Study was conducted in the Department of General Surgery, Index Medical College and Hospital, Indore from May 2013 to April 2016 (Three Years), 100 patients admitted to surgical emergency with acute abdomen were selected for the study. Proven to be cases of perforation peritonitis on the basis of investigations, if Laparotomy diagnosed to be case of caecal perforation.All operations were done by group of three experienced surgeons and they all performed the same technique. All the procedures were carried with hand sewn method. The antibiotics were given in all groups after admission to hospital and before surgery with 3rd generation cephalosporin (cefotaxime, ceftazidime, ceftriaxone, etc.), Amikacin and metronidazole.

The surgical management was done as primary repair with omental patch, primary repair with defunctioning loop ileostomy, Right hemicolectomy with ileotransverse anastomosis, Right hemicolectomy with double barrel ileotransverse colostomy depending on pathology.

Comparative study was done between group A (Right hemicolectomy with ileotransverse anastomosis) and group B (primary repair with omental patch, primary repair with defunctioning loop ileostomy, right hemicolectomy with double barrel ileo-transverse colostomy). There was no selection criteria for patients.

\section{Results}

Table 1: Gender Distribution of Caecal Perforation

\begin{tabular}{|c|c|c|}
\hline Sex & No. & Percentage \\
\hline Male & 76 & $76 \%$ \\
\hline Female & 24 & $24 \%$ \\
\hline
\end{tabular}

Table shows the $(76 \%)$ males were found and the females $(24 \%)$.

Table 2: Comparison between Group A \& Group B for Wound Infection/ Serous Discharge. There was statistical significance in wound infection/serous discharge between group A and group B with $\mathrm{p}$ value $=0.047$

\begin{tabular}{|c|c|}
\hline Operative procedure & $\begin{array}{c}\text { Wound infection } \\
\text { serous discharge }\end{array}$ \\
\hline Primary repair with omental patch & 18 \\
\hline Primary repair with defunctioning ileostomy & 18 \\
\hline $\begin{array}{c}\text { Right hemicolectomy with ileo-transverse } \\
\text { colostomy }\end{array}$ & 04 \\
\hline $\begin{array}{c}\text { Right hemicolectomy with ileo-transverse } \\
\text { anastomosis }\end{array}$ & 05 \\
\hline
\end{tabular}

\begin{tabular}{|c|c|}
\hline Treatment category & Total \\
\hline A & 50 \\
\hline B & 50 \\
\hline TOTAL & 100 \\
\hline
\end{tabular}

Table 3: Comparison between Group A \& Group B for Anastomotic Leak/ Fistula. There was statistical insignificance found in between group A and group B with $\mathrm{p}$ value $=0.043$ in anastomotic leak/ fistula

\begin{tabular}{|c|c|}
\hline Operative procedure & $\begin{array}{c}\text { Anastomotic } \\
\text { leak / Fistula }\end{array}$ \\
\hline Primary repair with omental patch & 08 \\
\hline Primary repair with defunctioning ileostomy & 06 \\
\hline $\begin{array}{c}\text { Right hemicolectomy with ileo-transverse } \\
\text { colostomy }\end{array}$ & 00 \\
\hline $\begin{array}{c}\text { Right hemicolectomy with ileo-transverse } \\
\text { anastomosis }\end{array}$ & 01 \\
\hline
\end{tabular}

\begin{tabular}{|c|c|}
\hline Treatment category & Total \\
\hline A & 50 \\
\hline B & 50 \\
\hline Total & 100 \\
\hline
\end{tabular}

Table 4: Comparison between Group A \& Group B for Outcome. There was statistical significance found in outcome between group A and group B with $\mathrm{p}$ value $=0.028$

\begin{tabular}{|c|c|}
\hline Operative procedure & $\begin{array}{c}\text { Outcome } \\
\text { (Death) }\end{array}$ \\
\hline Primary repair with omental patch & 04 \\
\hline Primary repair with defunctioning ileostomy & 02 \\
\hline $\begin{array}{c}\text { Right hemicolectomy with ileo-transverse } \\
\text { colostomy }\end{array}$ & 00 \\
\hline $\begin{array}{c}\text { Right hemicolectomy with ileo-transverse } \\
\text { anastomosis }\end{array}$ & 00 \\
\hline
\end{tabular}

\begin{tabular}{|c|c|}
\hline Treatment category & Total \\
\hline A & 50 \\
\hline B & 50 \\
\hline Total & 100 \\
\hline
\end{tabular}

\section{Discussion}

Most of the cases were of assault caused by multiple stab injury over body. The usual clinical picture was that of young adult recently stabed, who presented the typical signs and symptoms of surgical abdomen ${ }^{[5]}$. Free air was noted in the abdomen $20 \%$ of those patients roentgenografed. The average duration of perforation prior to surgical intervention was between 4 and 5 hours. Right hemicolectomy with ileo- transverse anastomosis was done in maximum cases.

Two deaths occured in traumatic caecal perforation as it had associated severe injury involving pelvis, scrotum, small bowel injury, chest trauma and other solid organ injury associated with severe haemorrhage ${ }^{[6]}$.

Iatrogenic caecal perforation is rare, but a serious complication associated with significant morbidity and mortality. The risk colonic perforation after diagnostic colonoscopy is reported as $0.03 \%$. In a recently published series of 110785 diagnostic and therapeutic colonoscopy procedures, a total of 14 incidence $(0.012 \%)$ of colonic perforation were reported.

Choo YC had reported a case of acute abdomen of a 46 year old male in Midwestern regional hospital, limerick with suspected appendicitis which turned out to be a perforated caecum, a rare complication of acute appendicitis ${ }^{[7]}$. Perforation at the base of ceacum was repaired with an absorbable suture and the omentel patch was used cover the caecum. In presence of uncomplicated perforation, absence of severe infection, and well controlled localized haemostasis, a less invasive approach with post operative intravenous antibiotic would be the management of choice $^{[8]}$. 


\section{Conclusion}

We recommend that right hemicolectomy with ileotransverse anastomosis should be preferred over other surgical options, primary repair with omental patch, primary repair with defunctioning loop ileostomy, right hemicolectomy with double barrel ileo-transverse colostomy in cases of caecal perforations in randomised study.

Right hemicolectomy with ileotransverse anastomosis in cases of traumatic caecal perforation plays an important role in reducing the incidence of complications like wound infection, wound dehiscenes, ileostomy and colostomy related complications like weight loss and electrolyte imbalance.

\section{References}

1. Vanek VW, Al-Salti M: Acute pseudo-obstruction of the colon (Olgivie's syndrome): an analysis of 400 cases. Dis Colon Rectum 1986, 29:203-210.

2. Tempia-Caliera AA, Horvath LZ, Zimmermann A, Tihanyi TT, Korc M, Friess H. Adhesion molecules in human pancreatic cancer. J Surg. Oncol. 2002; 79:93-100.

3. Carraro PG, Segala M, Orlotti C, Tiberio G: Outcome of large-bowel perforation in patients with colorectal cancer. Dis Colon Rectum. 1998, 41:1421-1426.

4. Yamamoto T, Hayashi Y, Suzuki H et al. Early onset of cecal perforation in neonatal, recto-sigmoid type Hirschsprung disease. Acta Pediatr Jpn. 1994; 36:717-9.

5. Brock W. Volvulus of the cecum. West J Surg Obstet Gynecol. 1954; 621:12-7.

6. DePalma RT. Nonobstructive cecal dilatation and perforation after cesarean section. Obstet Gynecol 1978; 52(1):61S-63S.

7. Choo YC. Ileus of the colon with cecal dilatation and perforation. Obstet Gynecol. 1979; 54(2):241-5.

8. Dumont M, Dovy D. Spontaneous perforation of the cecum after cesarean section. Rev Fr Gynecol Obstet. 1967; 62(10):531-3 